\title{
The understanding of Different Ethical Codes of Conduct by Healthcare Professionals in Nakuru District Government Hospitals
}

\author{
Juma Fredrick Okoiti \\ Egerton University 2014
}

\begin{abstract}
This paper discusses the understanding of different ethical codes of conduct by healthcare professionals in Nakuru district government hospitals. The main objective was to evaluate the understanding of the ethical codes of conduct by healthcare care workers when discharging their duties to the HIV/AIDS patients. Rule utilitarian theory by Jeremy Bentham and John Stuart Mill, was used as principled criteria in this work to assess the consequences of not adhering to codes of conduct in medical practice. The study employed descriptive research design. The target population for the study was all healthcare professionals in government district hospitals in nakuru district. The sampling was purposive for both healthcare professionals and HI/AIDS patients. The study used a questionnaire that was specific for healthcare workers in its data collection. 11 doctors, 91 nurses, 13 clinical officers and 10 laboratory technicians answered the questionnaire. The findings revealed that most healthcare professionals (97\%) do apply ethical codes of conduct in treating HIV/AIDS patients while (3\%) did not swear with any code of professionalism. It is hoped that the healthcare practitioners, philosophers and other relevant government departments will find this work useful in executing their professional duties.
\end{abstract}

\section{Introduction}

The understanding of ethical codes of conduct by healthcare professionals to patients is of great importance. The paper addresses the various aspects of ethical problems and questions, particularly how healthcare professionals relate to patients during treatment. It stipulates different ethical codes of conduct in the light of utilitarian theory of Jeremy Bentham (1749-1832) and John Stuart Mill (1806-1873). The paper also looks into the content of different ethical codes of conduct and what they state.

\subsection{Definition of Terms}

Ethical Code of Conduct Healthcare Professionals Rule- Utilitarianism - Refers to a set of guidelines that guarantee professionalism -Refers to those professionally trained to offer medical care to patients

-A theory that a person ought to act in accordance with the rule and if followed, it would produce the greatest balance of good over over evil, everyone considered. HIV/AIDS Patients -Persons infected with Acquired Immune-Deficiency Virus/ Human Immuno-Deficiency Syndrome disease.

\subsection{Objective.}

1. To establish whether healthcare professionals in Nakuru district government hospitals understand ethical codes of conduct of their profession.

\subsection{Hypothesis}

1. The Healthcare Professionals in Nakuru district government hospitals do not understand professional ethical codes of conduct prescribed in their training while handling HIV/AIDS patients.

\subsection{Research Questions}

To achieve the objective of this study, two sets of questions were raised;

i) Questions for the healthcare professionals, touching on their duties to HIV/AIDS patients, doctors' knowledge on their professional ethical codes of conduct and their training as medical professionals.

ii) Questions for the HIV/AIDS patients, touching on how healthcare professionals relate to them in terms of management, confidentiality of HIV/AIDS medical records and the attitude of healthcare professionals towards HIV/AIDS patients. 


\subsection{Significance of the Study}

Since the discovery of HIV/AIDS in Kenya in 1984, no clear guidelines have been spelt out to society, including the healthcare professionals as to how to manage HIV/AIDS patients due to the complexity of the disease. Healthcare professionals can improve both ethically and professionally only if they understand their different ethical codes. Although there has been several researches done on HII/AIDS, many have dwelt on prevention and treatment, overlooking management and care of those already infected. HIV/AIDS patients, just like those suffering from diabetes or cancer can still live longer if well managed by the society in general and the healthcare fraternity in particular by helping them eliminate stigma and fear. It is assumed that some of these patients die prematurely purely due to lack of professionalism by the medical staff while handling them. The study will contribute to the body of knowledge in the area of medical professionalism. The findings will enlighten the upcoming scholars, researchers, policy makers and healthcare workers on issues of ethical professionalism.

\subsection{Introduction}

\section{Related Literature}

The main purpose of this paper is to critically evaluate different ethical codes, taken by healthcare professional. It examines the Hippocratic Oath taken by doctors and other ethical codes of conduct taken by other healthcare workers in their profession. The study offers a framework to understand HIV/AIDS related stigma and discrimination effects. It highlights how the healthcare professionals are trained and their different ethical codes of conduct which they take after the training or in line with their duties. . It is a philosophical assumption that when these different ethical codes of conduct are understood and upheld, stigma and discrimination can be alleviated, improving standards of life to those infected.

\subsection{Moral dilemmas in medical practice}

In response to the increasing number and importance of moral dilemmas in medical practice, hospitals have formed ethics committees to handle ethical issues that arise from the management of HIV/AIDS and other illnesses. These issues constitute an increasing concern for human rights, including the problem of informed consent before medical intervention and the increased strength of the consumer movement with demand for better information on healthcare and various aspects of treatment, Ryan (2010). The term 'ethics committee' under discussion should not be confused with ethics committees for research.

Ethical committees have been initiated by physicians themselves and have become common in medical institutions worldwide, including Kenya. They evaluate the objectives of intended research projects and protect patients from being used without their consent. It might be asked why medical practice alone among many professions has attracted fulltime attention of so many ethicists. An answer to this is that the public is more concerned with their body health than with their financial or political well-being. A more relevant explanation is the change in the doctor-patient relationship, the affluence of the medical care system and the activities of the medical profession itself, Stroll (2010).

A final reason for the need of professionalism in medicine is the appointment of consultant ethicists as hospital staff. Also it has alerted many physicians and other healthcare professionals in general to be extra careful when making a medical judgment. This brings in utilitarianism debate that was developed by Jeremy Bentham (1749-1832) and John Stuart Mill (1806-1873). The deontological system was also expounded by Immanuel Kant, (1886). Deontology proclaims there are universal rules for behaviour, and intuitively understood by a rational man. By reflection, all rational persons know what is right or what correct conduct is. Kant (ibid) believed that there was one supreme moral law which states that all men should act only on those maxims capable of being willed as universal laws and no person should be treated as a means, but always as an end, since all people have intrinsic moral worth that needs to be respected. More contemporary deontologists have expanded this monistic approach to a pluralistic one. They state that our common moral convictions are composed of a plurality of principles that cannot be reduced to one another as to some higher single principle. Ross (1980) believes that the so-called prima facie moral obligations (obvious on the face of it or at first sight) can be listed by reflection upon and analysis of our intuitions. Besides principles which apply to everyone as a rational being, there are also particular duties that apply to those with special roles as doctors. Physicians have a particular duty to their patients, to promote their health and respect their confidence to avoid stigma and discrimination.

\subsection{Hippocratic Oath and Other Ethical Codes of Conduct}

The ethical codes of conduct attempt to formalize values and standards by raising a number of questions about profession and the consequent moral implications for behaviour which touches on professionalism. This study points out that unethical behaviour of healthcare professionals contributes to the suffering and pain of HIV/AIDS patients and yet medicine is supposed to be a life of service to the patients, to 
their families and to society. The ideal motto for the physician is caritas et justitia, which means "love and justice". Expressed in another way, the purpose of medicine is sometimes to cure, often to relieve, and always to console, Dunn (1999).

The first and most succinct formulation of the duty owed by a doctor to his patients is contained in the Hippocratic Oath written in Greece sometime in the $5^{\text {th }}$ century BC by Hippocrates, the man who was recognized as the father of western medicine. Hippocrates states "I will prescribe regimens for the good of my patients according to my ability and my judgment and never do harm to anyone", Jonsen (1990). Although the language of the oath has evolved through the ages, its essence remains the same and continues to guide modern medical ethics throughout the world. This duty has been recognised by law as a doctor's (and other medical practitioners') 'duty to take care' and applies irrespective of whether he has signed a contract of service with the patient, incorporating or excluding such duty.

The underlying assumption is that a person who offers medical advice and treatment implicitly states that he has the skill and knowledge to do so, to decide whether or not to take the case, to determine the nature of the treatment and to administer the treatment. If, therefore, in his treatment, a doctor deviates from accepted standards of practice and causes injury to or death of a patient, he is guilty of professional negligence and liable to pay damages to the patient or his/her next of kin.

The law on medical negligence has been developed considerably in the West where doctors maintain professional liability insurance to offset the risk of claims brought against them for professional negligence. In all instances, however, a doctor can only be held liable if the person suing him succeeds in proving or the situation is so clear that it speaks for itself that the doctor is guilty of a failure that no doctor with ordinary skills would be guilty of if acting with reasonable care. Doctors cannot, nor are they expected to, guarantee either their skill or the outcome of the treatment. All they can do is act with reasonable care.

One solution is to enable persons to seek redress through consumer courts, as is being done in India. These courts are located in smaller districts and a person may appear before them without a lawyer. Here too, however, he would still need to establish that the injury or death was a result of an act or omission of the doctor. It is unlikely that a layperson would be sufficiently savvy or have access to necessary materials, to make the legal connection between the outcome, of which he complains, and the treatment he was given.

In any event, redress through the courts is a remedy after the fact and offers little comfort to a person facing the prospect of losing a limb or his life. Therefore, more important than allowing greater access to courts and enhancing the penalties for negligence are to take steps to prevent negligence from occurring in the first place.

While recognising not only that doctors owe a fundamental duty of care to their patients but also that there is need to reform the present legal framework of the profession, it is essential to ensure that the focus of all reform is on distinguishing those doctors that act in good faith and to the best of their ability from those that are negligent, rash or reckless and on punishing only the latter with appropriate and objective severity. A solution lacking this balance will drive out any good doctors that may still remain in the country and leave the field open to their less vigilant peers to play with the lives of patients according to their whims. This study points out that the unethical behavior of some healthcare professionals contribute greatly to the suffering and pain of HIV/AIDS patients. However, Pace and Dougall (1978), state that doctors and other healthcare professionals have a moral obligation to always act in the best interest of their patients, provided they keep within their own moral and ethical principles as stated in the Oath;

I will maintain the utmost respect for human life from time Of conception, even under threat, I will not use my medical knowledge contrary to the laws of humanity. Geneva Declaration (1948).

In San Francisco, for instance, the medical treatment was withheld to some patients and the main reason for not treating or stopping treatment were either futility of further treatment, extreme suffering or requests by the patients' families "DNR" (Do Not Resuscitate) orders which preceded the actual withholding or withdrawing of further treatment and as per Hippocratic Oath, this is quite un ethical as it is stated;

I will use those dietary regimens which will benefit my patients according to my greatest ability and judgment and I will do no harm or injustice to them.

I will neither give deadly drug to anybody if asked for it, nor will

I make a suggestion to this effect. Lasagna (2001).

Medical understanding of these duties has been affected by three different currents of thinking as stipulated by Jonsen (1990). The first current is the one flowing from the origins of modern medicine in the Ancient Greek world, which has undergone various changes from time to time as indicated.

\subsection{Theoretical Framework}

It is essential for healthcare professionals worldwide to appreciate the moral implications of the medical decisions they make based on their understanding. This is despite that philosophy and medical ethics is a topic which is to a large part neglected in many undergraduate medical curriculums, Goodin, (1995). The 
philosophical theory of utilitarianism examines this doctrine in the context of healthcare professionalism. The utilitarianism as an ethical theory is a type of consequentialism which assesses actions on their outcome. The value of the action is assessed purely on its overall benefaction to utility, based on goodness or badness of the action. The study used an ethical theory which provides a framework that can be used to determine what is right and morally wrong regarding human actions professionally. It used theories of right and wrong that commanded the attention in the $20^{\text {th }}$ century. This is frequently reflected in arguments advanced in biomedical ethics. It gives a framework with which a person can correctly determine on any given occasion, what he or she morally ought to do, either as a professional or as a rational Being and subsequently, Kant's philosophy of universal moral laws is evident in the physician's thinking, whereby throughout his/her training, he/she is taught to save life.

Ethical issues are grouped into two main classes, namely the teleological and the deontological. The teleological claims that rightness and wrongness of human action is exclusively a function of the goodness and badness of the consequences, resulting directly or indirectly from the actions while the deontological in contrast states that the rightness and wrongness of a human action is not exclusively a function of the goodness or badness of the consequences. The study used the teleological ethical theory, which is also known as utilitarian theory which was propagated by two scholars, Jeremy Bentham (1748-1832) and John Stuart Mill (1806-1873), who introduced what was called "felicific calculus", which was a form of calculation that was used to determine whether an act was good or bad depending on the happiness resulting from it. The two philosophers argued that the main goal of utilitarianism was to minimize pain, misery and suffering, which is part of what Hippocratic Oath of doctors and other ethical codes of healthcare state, namely "Do no harm".

The two scholars differentiated between act-utilitarianism and rule- utilitarianism, and in this regard, referring to healthcare professionals, rule-utilitarian theory becomes quite appropriate in that it refers to a code of conduct. It establishes a moral code by reference to the principle of utility whereby a person ought to act in accordance with the rule that if generally followed, then would produce the greatest balance of good over evil, everyone considered. The rule being referred to in this case is specifically the Hippocratic Oath of doctors and other ethical codes that are taken by professional healthcare workers.

\subsection{Introduction}

\section{Methodology}

This chapter deals with procedures that were employed to carry out this research. The research survey method was used to establish the application of professional ethical issues by healthcare professionals.

\subsection{Research Design}

The study employed the ex post facto research design. Qualitative analysis of variables was done. It was non- empirical which involved a philosophical analysis. This involved critical examination of the relationship between the variables under the study.

\subsection{Population of the Study}

The target population for the study included doctors, nurses, clinical officers and laboratory technologists. In total, the researcher interviewed 11 doctors, 91 nurses, 13 clinical officers, 10 laboratory technicians and $120 \mathrm{HIV/AIDS}$ patients, totaling to 245 respondents.

\subsection{Sampling and Sampling Procedure}

For the purpose of collecting data for this research, non probability sampling method was used which comprised of purposive sampling and snow ball sampling.

\subsection{Data Collection Tools}

Many tools were used in this research but the main one was the questionnaire, though library and Internet were also used.

\subsection{Data Analysis}

Data collected was coded and analysed using both descriptive and inferential statistics involving ANOVA, Pearson, Correlation Coefficient and Chi-Square. Qualitative data was analysed thematically. Data analysis was done with the aid of the computer based Statistical Package for Social Sciences (SPSS). Tables, means, averages, and percentages were also used.

\section{Results and Discussions}

The paper presents the results and discussions of the study findings. The data was analysed using descriptive and inferential statistics aided by Statistical Package for Social Sciences (SPSS). The hypotheses were tested by application of a Chi-Square Test. Both hypotheses tests were performed at a significance level of 
$a=.05$. Acceptance or rejection of the null hypotheses was based on the calculated test statistics, and the value of the probability of significance ( $p$ value). The null hypothesis was accepted if $p>.05$ and rejected if $p<.05$. The results are presented in form of tables and figures.

\subsection{Understanding of Ethical Codes of Conduct by Healthcare Professionals}

This section considered views of HIV/AIDS patients regarding how they were handled by the healthcare professionals from different government healthcare institutions within nakuru district.

\begin{tabular}{ccc}
\multicolumn{3}{c}{ Table 1: Total Numbers of HIV/AIDS Patients in District Hospitals } \\
\hline Hospital & No. & Percentage \\
\hline Naivasha & 43 & 36 \\
Gilgil & 22 & 18 \\
Molo & 55 & 46 \\
Total & 120 & 100 \\
\hline
\end{tabular}

Table 1 shows the total numbers of HIV/AIDS patients within Nakuru district government hospitals that were involved in the study. The study findings revealed that $(46 \%)$ of the HIV/AIDS patients were from Molo district hospital, (36\%) were from Naivasha district hospital and (18\%) were from Gilgil district hospital. Since HIV/ADS were recognized in Kenya in 1984, the scourge has had a devastating effect to both Kenyan economy and to society at large. There have been different efforts from Non-Governmental Organisations and Kenya government to try and fight the scourge and indeed this campaign brought about some changes which reduced the prevalence rate from (14\%) in 2000 to $(6 \%)$ in 2011. NACC,(2011).

The National AIDS Control Council (2011) and UNAIDS (2009) reported that 40 million people live with AIDS in the world, whereby 35.3 million live in Africa. Between 1983 and 1985, 26 cases of AIDS were reported in Kenya, UNAIDS, (2004). Sex workers were the first group to be affected according to UNGASS, (2008). The same report indicated that most of the HIV/AIDS victims admitted in hospitals were mostly sex workers who in most cases engaged in unprotective sex. Apart from sex workers, the study also revealed a high HIV prevalence amongst other key groups including injecting drug users (IDUs), men who have sex with men (MSM), truck drivers and cross- border mobile populations.

Table 2: The Number of Healthcare Professionals Involved in the Study.

\begin{tabular}{lll}
\hline Profession & No. & Percent \\
\hline Doctor & 11 & 8.8 \\
Nurse & 91 & 72.8 \\
Clinical Officer & 13 & 10.4 \\
Lab Technician & 10 & 8.0 \\
Total & 125 & 100.0 \\
\hline
\end{tabular}

The study used a sample of 125 healthcare professionals, composed of 91 nurses (73\%), 13 clinical officers, (10\%), 11 Doctors $(9 \%)$ and 10 laboratory technicians, $(8 \%)$. From the above table, nurses had the highest number of 91 from the total of 150 in all healthcare institutions in this study. The study also established that there were very few doctors whom patients rely on for consultations and specifically in Gilgil, Naivasha and Molo district hospitals

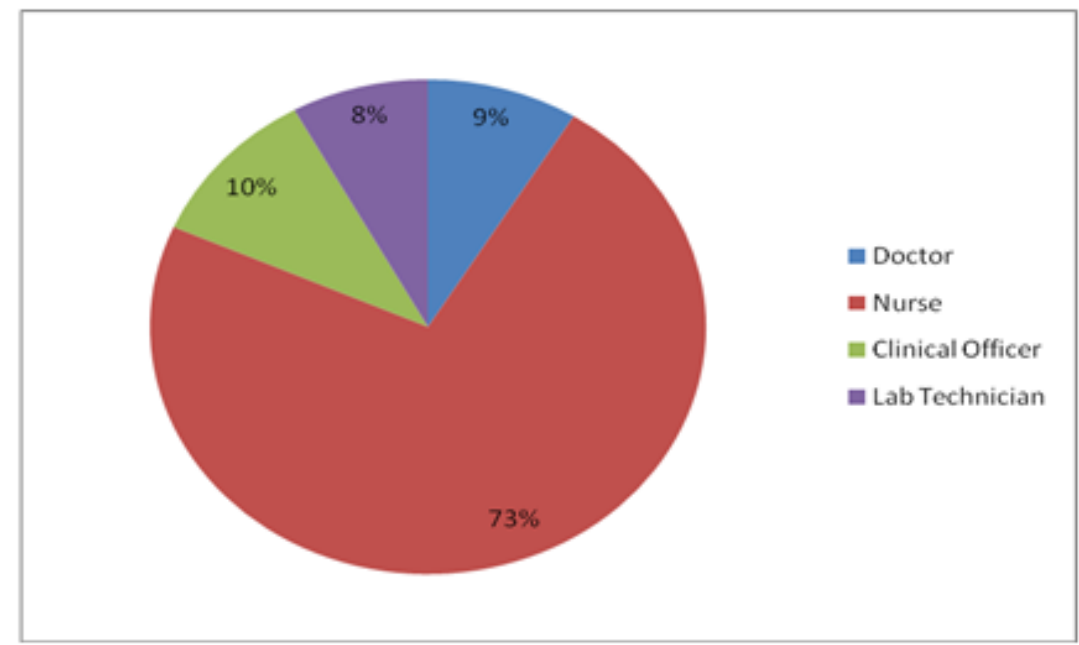

Figure 2: Percentage of Participants from Government Hospitals 
Figure 2 indicates the percentage of participants from government hospitals. The nurses had the highest number of $(73 \%)$, and the laboratory technicians were the least with $(8 \%)$. The difference in percentage was due to the fact that the nurses were the majority in comparison to other healthcare professionals. The ethical issues in healthcare start from the very questions which confront today's medical scientists and the whole of mankind in society. They are issues which the medical profession questions itself seriously about the care of patients. In this case, ethical issues arise in management of HIV/AIDS patients. Over the years, there has been much talk about the loss of ethos of medical staff or the eminent danger of its loss and at the same time, the healthcare professionals have engaged more than ever before in discussions on ethical issues arising from their profession, Haring (1995). The healthcare professionals should inspire the minds of their patients with gratitude, respect and confidence.

Table 3: Distribution of Healthcare Professionals in Government Hospitals

\begin{tabular}{lll}
\hline Location & No. & Percent \\
\hline Naivasha & 35 & 28 \\
Gilgil & 29 & 23 \\
Molo & 59 & 47 \\
Nakuru & 2 & 2 \\
Total & 125 & 100 \\
\hline
\end{tabular}

Table 3 shows the distribution of district government hospitals and the number of healthcare professionals involved in the study. Molo hospital had the highest number of 59, consisting of (47\%), Naivasha hospital had 35 healthcare professionals, consisting of (28\%), Gilgil hospital had 29 healthcare professionals, consisting of $(23 \%)$ and Nakuru hospital had the least number of staff members, consisting (2\%).

Table 4: Healthcare Professionals who took the Ethical Code of Conduct

\begin{tabular}{lll}
\hline Response & No. & Percent \\
\hline Yes & 121 & 97 \\
No & 4 & 3 \\
Total & 125 & 100 \\
\hline
\end{tabular}

Table 4 shows the frequency and percentage of healthcare professionals who took an oath of their profession. The Majority of the respondents, 121 representing (97\%) indicated that they had taken an oath of their profession, while 4 respondents, representing (3\%) said they had not taken any professional oath.

The healthcare ethical codes of conduct basically set out two sets of duties. It spells out duties to the patient and duties to other members of the profession, Percival, (1803). Code of ethics make explicit the primary goals and values of the profession. When individuals become healthcare professionals, they make moral commitment to uphold the values and special moral obligations expressed in their code. The code for nurses for instance is based on belief about the nature of individuals, nursing, health and society, The Code of Ethics for Registered Nurses, (1980). It in compasses the protection, promotion and restoration of health, the prevention of illness and the alleviation of suffering in the case of clients, including individuals, families, groups and communities.

Ethical codes are necessary in making clinical judgments whose decisions are based on considering the consequences and of universal moral principles, both of which prescribe and justify healthcare actions. The statements of the ethical codes of conduct and their interpretation provide guidance for conduct and relationships in carrying out healthcare responsibilities consistent with ethical obligations of the profession with high quality nursing care.

The healthcare personnel need to offer professional services and their professionalism ought to be guided by the ethical principles at all times as stated in the Hippocratic Oath of doctors and in other codes of conduct for other health workers. This therefore is the necessary reason why healthcare professionals must undergo certain training and must also undertake some oath to safeguard healthcare profession. 


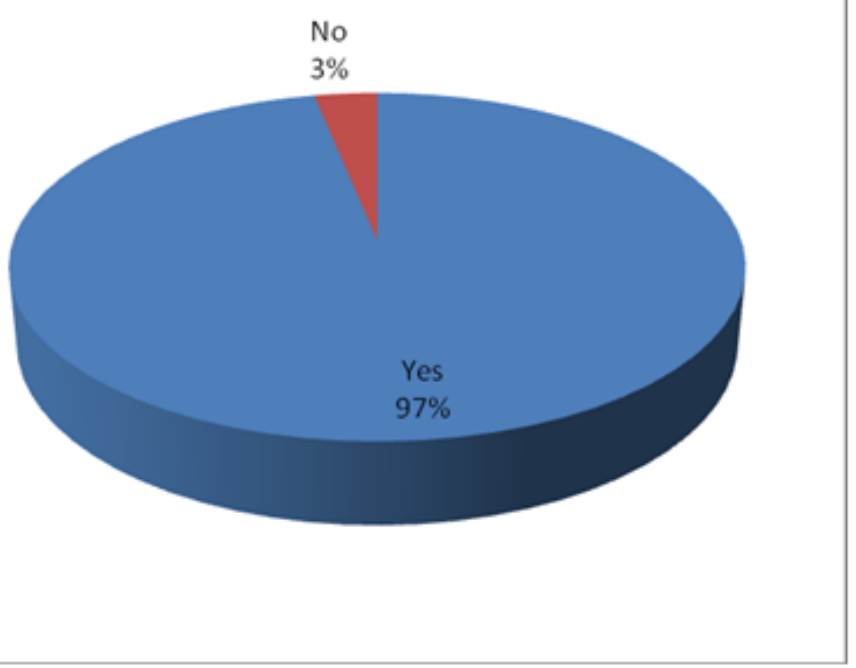

Figure 1: Percentage of those who took the Oath and those who did not

Figure 3 indicates in percentage the healthcare professionals who took the Oath and those who did not. (3\%) of healthcare professionals did not undertake any Oath of their profession and yet the underlying assumption is that any person offering any medical treatment or advise ought to have taken an Oath. According to Edge and Grove (1994), a code of conduct means that as a healthcare professional, one must have the responsibility to work to standard which is stipulated within the Oath. The (3\%) who did not undertake the Oath raise the question of whether they underwent proper medical training or not. However, (97\%) of the healthcare professionals undertook ethical codes of conduct of their profession, to provide services with respect for human dignity and uniqueness of the client, unrestricted by considerations of social or economic status, personal attributes or the nature of health problems.

Table 5: Distribution of Healthcare Professionals Who Took the Oath of their Profession

\begin{tabular}{|c|c|c|}
\hline Name of profession & Yes $\quad \%$ & No \\
\hline Doctors & 11 & 0 \\
\hline Nurses & $90^{\circ}$ & 1 \\
\hline Clinical officers & $\mathrm{YI}^{-}$ & 2 \\
\hline Laboratory Techician & 9 & 1 \\
\hline
\end{tabular}

Table 5, shows distribution of the individual healthcare professionals who took their codes of conduct respectively. It indicates that the largest number of healthcare professionals who took their oath were nurses, followed by doctors. The codes of conduct are different for different professions but they all have one theme in common, namely, to maintain the highest standards of professional conduct. All doctors took oath of their profession, and 90 nurses out of 91 had also taken the ethical code of conduct that governs their profession. There were 11 clinical officers who took their oath and 9 laboratory technicians out of 10 had taken their professional oath.

The Ethical Code of doctors (2004), The International Ethical Code for Nurses, (1994), International Nursing Council (1973) and The Code of Professional Conduct for Medical Laboratory Technologists (2004), all stipulate duties for each profession. The Ethical Code for doctors, (2004), demand that the doctor must always bear in mind the obligation of preserving human life from conception. The patient is owed complete loyalty and the doctor must always preserve absolute secrecy concerning all he/she knows about a patient because of the confidence trusted in him. The doctor must observe the principles of the Declaration of Geneva, (1948), which is understood as part of the Hippocratic Oath.

The clinical officers and the nurses are bound to their duties by the International Ethical Code for Nurses, (1973). The codes of conduct stipulate the area of responsibility for the nurse as to carry out nursing care, to communicate, manage and develop nursing which is directed toward people in need of nursing. The clinical officer and the nurse amongst other duties ought to safeguard the clients' right to privacy by judiciously protecting information of a confidential nature. They must act to safeguard the client and the public when health care and safety are affected by the incompetent, unethical or illegal practice of any person, and assume responsibility and accountability for individual nursing judgments and actions. The clinical officer and the nurse should have integrity. The code for laboratory technologists demand that they must be dedicated, must work 
with other healthcare professionals, must promote the image and status of the profession, protect confidentiality of patient information and be able to take responsibility for their professional acts among other duties.

\subsection{Training of Healthcare Professionals}

For one to become a doctor or a healthcare expert, it is mandatory to complete a course study prescribed by a medical board. In Kenya, a doctor must complete a minimum of 5 years training which comprises of the first two years in classroom work, learning basics of anatomy, diseases and body functions. The remaining of medical training is comprised of clinical, hands-on-patient work, usually in a teaching hospital or an academic medical centre which comprises of Internship. Other professions like clinical officers and nurses also undergo training in their areas which take a minimum of 4 years, under the supervision of clinical practice and Internship at an accredited medical training institution and hospitals, who should again register with the relevant medical board of their country, Haring,(1991).

Table 6: Training of Healthcare Professionals on HIV/AIDS

\begin{tabular}{lll}
\hline Statement & No. & Percentage \\
\hline $\begin{array}{l}\text { Healthcare professionals trained in } \\
\text { management of HIV/AIDS }\end{array}$ & 121 & 97 \\
$\begin{array}{l}\text { Those not trained in management } \\
\text { HIV/AIDS }\end{array}$ & 4 & 3 \\
TOTAL & 125 & 100 \\
\hline
\end{tabular}

Table 6, indicates that majority of the respondents (97\%) had some form of training in the management of HIV / AIDS patients, while (3\%) indicated that they did not have any training on the same. This raised questions as to whether the training of the healthcare professionals on handling patients with special cases like HIV/AIDS is part of their syllabus or these skills are simply acquired through workshops.

According to Dunn (1999), when medical students graduate, they recite the following;

I solemnly pledge myself to consecrate my life to the service of humanity. I will practice my profession with conscience and dignity. I will not permit considerations of religion, nationality, race, party politics or social standing to intervene between my duty and my patient, (Pg 68).

Dunn states that the above quote should also include non discrimination of patients because of their HIV status. This is recited in various ethical codes like those of doctors, clinical officers and nurses as expressed in The Declaration of Helsinki, (1964), The Declaration of Sydney, (1968), The Declaration of Oslo, (1970), The Declaration of Tokyo,(1975), The Islamic Code,(1980) and many more others.

Table 7: Clinical Experience in Managing HIV / AIDS Patients

\begin{tabular}{lll}
\hline Statement & No. & Percentage \\
\hline $\begin{array}{l}\text { Healthcare professional with sufficient knowledge on how to } \\
\text { advice HIV/AIDS patients and their families }\end{array}$ & 104 & 83 \\
$\begin{array}{l}\text { Healthcare professionals with insufficient knowledge } \\
\text { Total }\end{array}$ & 21 & 17 \\
\end{tabular}

Table 7 shows that majority of the respondents (83\%) indicated they had sufficient knowledge and experience of advising HIV /AIDS patients, their families and friends, while (17\%) had insufficient knowledge.

The experience level of healthcare personnel in managing HIV/AIDS patients can adequately be evaluated by their competence. Buchanan, (1975), argues that competence evaluations must strike a balance between the values of a patient, self determination and the patient's well being, by protecting the patient from harm that might result from inexperienced staff. Buchanan states that no single standard of experience is appropriate for decision making. Consultation therefore become a necessary tool within the medical fraternity, despite the number of experienced years in the profession and this is more emphasized when dealing with HIV/AIDS patients.

Table 8: Period of Training Healthcare Professionals

\begin{tabular}{lll}
\hline Training period of healthcare professionals & No. & Percentage \\
\hline $1-3$ years & 66 & 53 \\
$3-10$ years & 52 & 42 \\
Above 10 years & 7 & 6 \\
Total & 125 & 100.0 \\
\hline
\end{tabular}

Table 8 indicates that (53\%) of healthcare professionals had been trained for not more than 3 years, (42\%) were trained between 3 to 10 years and (6\%) indicated above 10 years. In Kenya, Medical training for a doctor takes a minimum of 5 years to be awarded a bachelors degree in medicine and surgery (MB chB). This is 
followed by one year period of Internship. In other African countries like Ghana and Egypt the basic medical education lasts for 6 years.

After training, the healthcare professionals require permission from their respective countries to practice. Such permission is intended to promote public safety and protect the public from any unprofessional service, (WHO, 2010). In Kenya for instance, The Medical Practitioners and Dentist Board is a statutory authority established by the Kenya government under cap 253 Laws of Kenya. It is meant to regulate the practice of medicine and dentistry in the country. The aims towards offering Kenyans the most effective and efficient medical services available by ensuring the medical practitioners and dentists are highly qualified and ensure that they continuously develop their career through short courses and retraining.

Table 9: Understanding of the Hippocratic Oath and other Ethical Codes by Medical Practitioners

\begin{tabular}{lll}
\hline Statement & No. & Percentage \\
\hline Healthcare professionals who have read and understood & 89 & 71 \\
Hippocratic Oath and other ethical codes & & \\
Those who did not read and understand their ethical codes. & 36 & 29 \\
Total & 125 & 100 \\
\hline
\end{tabular}

Table 9 shows the level of understanding of the Hippocratic Oath and other ethical codes for the healthcare professionals. When asked whether they had read the Hippocratic Oath or any other code of conduct for their profession, the majority of the respondents $(71 \%)$ said yes, while (29\%) said they had not. The majority who had read the codes of conduct of their profession indicated that most of them emphasized the high degree of professional conduct as regards the doctor-patient relationship. The minority either had no opinion or could not remember anything from the oath of their profession.

Every trained healthcare professional ought to comprehend or be aware of the ethics of that profession and the eminent danger of its loss. Medical profession has engaged more than ever before in discussions on ethical questions arising from its field. There is a relationship between ethos and different ethical codes which guide professional groups. It fosters adherence to certain values. Haring,(1995). Ethical code consists of a studied effort to foster and guarantee the ethos and for the healthcare professionals, it is meant to go beyond by assuring patients and the public a professional standard of human relationships. No other professional community has elaborated an ethical code so early in its history and as universally as has the medical profession. This therefore makes it mandatory for the healthcare professionals to read and understand their different ethical codes that guide their profession.

As a conclusion therefore, the majority of Healthcare professionals in government hospitals in Nakuru district understood ethical principles while handling HIV/AIDS patient and the hypothesis which stated that "'that the healthcare professionals in Nakuru district government hospitals do not understand the professional ethical codes of conduct and principles while handling HIV / AIDS patients" is therefore rejected.

\section{Summary and Conclusion}

The purpose of this study was to examine whether healthcare professionals in Nakuru district government hospitals did adhere to and are guided by professional ethical codes of conduct and principles in the discharge of their duties in handling HIV/AIDS patients. The study also examined Independent variables which were codes of conduct, confidentiality, professionalism, privacy and doctor-patient relationship, and these had effect on the dependable variables. The findings were therefore summarized as follows;

i. The majority of healthcare professionals, (97\%) indicated they had been trained on HIV/AIDS management and had professional knowledge on how to manage and advise infected patients, families and their friends.

ii. The study revealed that the majority of the healthcare professionals, (71\%) understood and have read different codes of ethics and conduct which emphasize professional conduct as regards doctor-patient relationship.

iii. The study established that confidentiality of HIV/AIDS patients' records were fairly kept confidential. $(73 \%)$ describing it as good, while $(13 \%)$ described it as very good.

iv. The study established the majority of healthcare professionals, (97\%) adhered to and were guided by professional ethical codes of conduct and principles in the discharge of their duties on HIV/AIDS patients.

In conclusion, it was established that the highest percentage of healthcare professionals was well trained and their level of professionalism was quite high. 


\section{References}

[1]. Annas, G. (1975). The Rights of Hospital Patients. New York: Avon Books.

[2]. Delor, F and M. Hubert. (2000)."Revisiting the Concept of 'Vulnerability'. Social Science \& Medicine. 50: 1,555-1,570.

[3]. Dunn, H.P. (1999). Ethics for Doctors, Nurses and Patients. New York: Alba House.

[4]. George, A. (1975). The Fundamental Concept of Informed Consent. New York: Harper and Row.

[5]. Godkin, D, Markwell H.(2003). The duty to care of healthcare professionals: ethical issues and guidelines for policy development. Toronto: Joint Center for Bioethics, University of Toronto; Guidelines of the Code of Ethics for Nurses, adopted may 1992 at the DNO's Congress.

[6]. Goffman, E. (1963). Stigma: Notes on the Management of Spoiled Identity. New York: Simon and Schuster.

[7]. Goodin,R.E. (1995). Utilitarianism as a Public Philosophy. Cambridge. Cambridge University Press.

[8]. J.S. Mill (1972). Utilitarianism, Liberty, Representative Government. Ed by H.B. Acton. London: J.M. Dent and Sons.

[9]. Jonsen, A. (1990). The New Medicine and Old Ethics. Cambridge: Havard University Press.

[10]. Lasagna, V. (2001). Introduction to Ethics. New York. Yale University Press.

[11]. Mill,J.(1863). Utilitarianism. London: Cambridgeshine. Retrieved from www.utilitarianism.net/jsmill.

[12]. Shenken, D. (1991). Managing HIV/AIDS Patients. Oxford. Oxford University Press.

[13]. Smart,J. (1995). Extreme and Restricted Utilitarianism. Oxford: Oxford University Press.

[14]. Strax,T.E. (1994). "Ethical Issues of Treating Patients with Aids in a Rehabilitation

Setting” American Journal of Physical Medicine and Rehabilitation. 73, 293-295.

[15]. UNAIDS._AIDS Epidemic Update (December 2003).

[16]. UNAIDS. AIDS Epidemic Update. (November 2009).

[17]. UNAIDS. AIDS Epidemic Update. (February 2012). 